\title{
Keterikatan Interpersonal pada Beberapa Etnis Besar di Indonesia
}

\author{
H. Fuad Nashori1*, Muh. Nurhidayat Nurdin2, Netty Herawati3, \\ Raden Rachmy Diana4, \& Alifah Nabilah Masturah5 \\ ${ }_{1}$ Program Magister Psikologi Profesi (S2), Universitas Islam Indonesia, Yogyakarta, Indonesia \\ 2 Fakultas Psikologi, Universitas Negeri Makassar, Makassar, Indonesia \\ 3 Program Studi Psikologi, Universitas Trunojoyo, Bangkalan, Indonesia \\ ${ }_{4}$ Program Studi Psikologi, Universitas Islam Negeri Sunan Kalijaga, Yogyakarta, Indonesia \\ 5 Fakultas Psikologi, Universitas Muhammadiyah Malang, Malang, Indonesia
}

\begin{abstract}
Abstrak
Walau bangsa Indonesia dianggap memiliki kebudayaan kolektivistik, masih belum diketahui apakah tiap-tiap kelompok etnis menekankan nilai-nilai kebersamaan dan harmoni sosial dalam level yang sama. Penelitian ini bertujuan untuk mengetahui perbedaan tingkat keterikatan interpersonal pada lima kelompok etnis besar di Indonesia. Jumlah subjek yang terlibat adalah 1.420 orang yang berasal dari etnis Jawa subkultur Negarigung, etnis Jawa subkultur Mancanegari, etnis Madura, etnis Minangkabau, dan etnis Bugis-Makassar. Data dianalisis dengan menggunakan teknik analisis varians untuk menguji perbedaan nilai rerata dalam keterikatan interpersonal. Hasil penelitian menunjukkan ada perbedaan yang berarti dalam hal keterikatan interpersonal antar etnis. Etnis Jawa Nagarigung cenderung lebih menonjolkan rasa percaya terhadap sikap dan perilaku mitra relasi dibanding etnis-etnis lainnya kecuali etnis Jawa Mancanegari. Sementara itu etnis Jawa Mancanegari cenderung lebih tinggi dalam persepsi kualitas hubungan dengan mitra relasi dibanding seluruh etnis lainnya kecuali etnis Minangkabau. Untuk dimensi kuatnya pertimbangan pihak ketiga dalam relasi, etnis Minangkabau cenderung lebih tinggi dibanding seluruh etnis lain. Dengan demikian, terdapat perbedaan antar etnis dalam menonjolkan dimensi keterikatan dalam hubungan interpersonal.
\end{abstract}

Kata kunci: keterikatan interpersonal, Jawa, Madura, Minangkabau, Bugis-Makassar

\begin{abstract}
Even though previous research suggested that Indonesia is a collectivistic society, we are still at the dark when we question whether each Indonesian sub-ethnic group actually differ in their endorsement toward collectivistic values. This study aimed to investigate whether there are meaningful differences in interpersonal attachment between five major ethnic groups in Indonesia. A total of 1.420 subjects from Javanese ethnic Negarigung subculture, Javanese ethnic Mancanegari subculture, Maduranese ethnic, Minangese ethnic, and Bugisese-Makassarese ethnic participated in this study. The data was analyzed with analysis of variance to determine whether there is any mean difference between ethnic group. The results showed that there were significant differences in interpersonal attachment. The Javanese Nagarigung ethnic tends to emphasize more trust in the attitudes and behaviors of the relational partners than other ethnic groups except the Mancanegari Javanese. Meanwhile, the Mancanegari Javanese tend to be higher in the perception of the quality of relations with partner relations than all other ethnic groups except the Minangkabau ethnic group. For the dimension of third-party consideration in relationships, the Minangkabau ethnicity tends to be higher than all other ethnic groups. Thus, there were differences between ethnic groups in highlighting the dimensions of engagement in interpersonal relationships.
\end{abstract}

Keywords: interpersonal relationship, Javanese, Maduranese, Minangese, Bugisese-Makassarese

\section{Pendahuluan}

Hubungan yang baik dengan orang lain itu penting dikarenakan berdampak positif baik untuk diri maupun secara sosial (Su-hsing \& Wei-ming, 2009; Nashori, Iskandar, Setiono, \& Siswadi, 2011; McCullough, Worthington, Rachal, Sandage, Brown, \& 
Hight, 1998). Kajian tentang hubungan yang baik antar individu diwadahi dalam wacana tentang keterkaitan interpersonal (interpersonal relation). Konsep ini dikembangkan oleh Hoorens dan Poortinga (2000). Hoerens dan Poortinga menggarisbawahi tentang adanya fenomena kehadiran orang lain yang mempengaruhi sikap dan perilaku individu. Individu bisa saja berpikir bahwa ia dapat mengambil keputusan sendiri tentang suatu hal. Namun, dalam kenyataannya, setiap individu dipengaruhi oleh orang lain.

Penelitian-penelitian sebelumnya tentang keterkaitan interpersonal (interpersonal relation) dilakukan dengan cara menghubungkannya dengan variabel lain (Downie, Mageau, \& Koestner, 2008; Li, Jiang,Yong, \& Zhou, 2018; Opič, 2016; Su-hsing \& Weiming, 2009), dicari perbedaannya antar-etnis (den Brok, Wubbels, Veldman, \& van Tartwijk, 2009; Shears \& Furman, 2005), antargender (Calmes \& Roberts, 2008), atau antar kepribadian. Sebagai contoh, keterikatan interpersonal berkorelasi positif dengan sifat kebaikan hati (agreeableness) dan berkorelasi negatif dengan trait neurotisisme (neuroticism) (Kurtz \& Sherker, 2003; Nashori, Wijaya, Diana, \& Herawati, 2019; Nashori, Iskandar, Setiono, Siswadi, \& Andriansyah, 2020).

Namun penelitian yang mengkaji perbedaan antar etnis dalam keterikatan interpersonal (interpersonal attachment) belum pernah dilakukan secara spesifik di kebudayaan Indonesia. Adapun yang sudah dilakukan adalah mengkaji hubungan antara variabel keterikatan interpersonal dan variabel lain seperti pemaafan, agreeableness, neuroticism, religiositas (Nashori, 2011; Nashori, 2012; Nashori, dkk., 2011; Nashori, Iskandar, dkk., 2019; Nashori, Wijaya, dkk., 2019). Walau sudah ada perbandingan tentang keterkaitan interpersonal (interpersonal relation) antar etnis dalam riset sebelumnya di kebudayaan Barat (den Brok, Wubbels, Veldman, \& van Tartwijk, 2009; Shears \& Furman, 2005), namun hasil riset itu sangat kontekstual dan tidak bisa digunakan dalam konteks perbedaan etnis seperti di Indonesia. Walau Indonesia dianggap sebagai bangsa dengan budaya kolektivistik yang sangat menjunjung tinggi nilai-nilai relasional, namun bisa jadi terdapat perbedaan antar etnis di dalamnya.

Penelitian ini memfokuskan pada perbedaan keterikatan interpersonal (interpersonal attachment) antar sejumlah etnis besar di Indonesia. Dengan demikian, topik tulisan ini memiliki orisinalitas dalam hal membandingkan keterikatan interpersonal antar etnis di Indonesia.

\section{Keterikatan Interpersonal antar Kelompok Etnis di Indonesia}

Keterikatan interpersonal (interpersonal attachment) adalah suatu kondisi psikologis saat individu sangat mempertimbangkan keberadaan orang lain dalam pengambilan keputusan atas hal-hal yang penting dalam kehidupannya, khususnya yang berkaitan dengan relasi interpersonal bersama orang lain. Keterikatan interpersonal memiliki beberapa dimensi. Berdasarkan penilaian tujuh ahli psikologi sosial Indonesia, dirumuskan oleh Nashori (2011), bahwa keterikatan interpersonal meliputi tiga dimensi. Pertama, persepsi individu terhadap sikap dan perilaku dari mitra relasi, yang meliputi persepsi adanya perubahan pada diri mitra serta persepsi terhadap komitmen mitra relasi untuk tidak mengulangi perbuatan yang merugikan. Kedua, kualitas hubungan individu dan mitra relasi, yang meliputi mengingat kebaikan mitra relasi serta komitmen melanjutkan hubungan yang akrab dengan mitra relasi. Ketiga, pertimbangan pihak ketiga kepada individu, yang meliputi permintaan dari orang lain yang berpengaruh (the significant others) serta dukungan dari lingkungan. Dimensi-dimensi ini telah mendapat konfirmasi dari para ahli psikometri dan ahli psikologi sosial bahwa keterikatan internasional meliputi tiga dimensi tersebut (Nashori, 2012).

Berdasar temuan lapangan diketahui bahwa etnis Jawa menunjukkan keterikatan interpersonal yang cukup menonjol. Salah satu bentuk kongkrit keterikatan interpersonal etnis Jawa adalah selalu mempertimbangkan masukan, usulan, saran, nasihat dari the significant person (Nashori, Iskandar, Setiono, Siswadi, \& Andriansyah, 2020). Di samping itu, berdasarkan penelitian Nashori (2011) pada etnis Jawa diketahui bahwa ada fenomena yang memiliki keunikan dari sekadar keterikatan interpersonal. Orang Jawa dikenal sebagai etnis yang merasa dirinya terikat dengan orang lain (Setiono, 2009). Oleh Nashori (2011), fenomena itu disebut sebagai keterikatan interpersonal (interpersonal attachment).

Penelitian ini bertujuan untuk mengetahui perbedaan keterikatan interpersonal antar sejumlah etnis yang ada di Indonesia. Penelitian ini menarik dilakukan pada berbagai suku di Indonesia, karena fenomena keterikatan interpersonal ini tampak berlangsung pada etnis-etnis di Indonesia, dalam hal ini adalah etnis Jawa subkultur Mancanegari, etnis Jawa subkultur Negarigung, etnis Minangkabau, etnis Madura, dan etnis Bugis-Makassar. Selain itu, sejauh ini belum ada penelitian yang mengungkap perbedaan keterikatan interpersonal antar etnis di Indonesia.

Pemilihan sejumlah etnis sebagai subjek penelitian didasari pandangan Naim (1979) bahwa ada dua kelompok besar etnis di Indonesia berdasarkan orientasi diri dan masyarakat. Etnisetnis yang bercirikan sentrifugal (memilah-milah untuk kemudian yang serasi disintesiskan, yang tidak serasi dibuang) adalah Minangkabau. Etnis-etnis Melayu, Bugis-Makassar, dan sebagainya bisa juga dimasukkan di sini. Etnis-etnis yang bercirikan sentripetal-sinkretis (menerima pengaruh dari luar tanpa usaha mensintesakannya) adalah Jawa, Sunda, Madura, Bali, dan sebagainya. Hal ini didasari oleh kenyataan bahwa sekalipun mereka sama-sama memiliki budaya kolektivistik, namun nilai budaya khas mereka berbeda satu sama lain. Dengan nilai 
budaya yang khas itu mereka menunjukkan keterikatan interpersonal yang tinggi namun dengan variasi yang berbeda. Mereka memiliki berbagai nilai budaya yang memungkinkan keterikatan interpersonal mereka tumbuh kembang secara optimal. Berikut ini penjelasan tentang nilai budaya yang mendasari keterikatan interpersonal pada berbagai etnis.

Pertama, keterikatan interpersonal etnis Jawa subkultur Negarigung dan subkultur Mancanegari. Etnis Jawa sendiri sering dibedakan menjadi lima subkultur (Koentjaraningrat, 1994), yaitu subkultur Negarigung (Yogyakarta, Surakarta, dan sekitarnya), subkultur Mancanegari (Surabaya, Malang, dan sekitarnya), subkultur Banyumasan (Purwokerto, Tegal, dan sekitarnya), subkultur Bagelen, (Purworejo, dan subkultur Pesisir, dan daerah kebudayaan di pantai utara Jawa, yang dibagi menjadi Pesisir Kilen (Pesisir Utara Jawa Tengah) dan Pesisir Wetan (Pesisir Utara Jawa Timur). Berkaitan dengan keterikatan interpersonal, orang Jawa memegang prinsip rukun (Susetyo, Widiyatmadi, \& Sudiantara, 2014).

Nilai budaya Jawa ini mengajarkan agar orangorang dalam etnis Jawa selalu rukun atau menjaga keharmonisan dengan orang lain. Dalam rangka menjaga keharmonisan, setiap individu diharapkan berusaha menjadi tenang atau meredam semua hal yang berpotensi memperuncing perselisihan dan pertentangan. Dicontohkan oleh Sartini (2009), untuk menjaga kondisi rukun, ada keharusan berhati-hati pada diri orang Jawa, seperti ngono yo ngono ning aja ngono (hendaknya tidak berlebihan dalam bertindak maupun berkata, serta mampu mengukur diri dan lingkungan sekitarnya). Ungkapan-ungkapan yang mengandung nilai rukun di atas hidup secara baik pada etnis Jawa dengan subkultur Negarigung. Selanjutnya, disebutkan oleh Sutarto (2004), etnis Jawa subkultur Mancanegari sedikit berbeda dengan etnis Jawa subkultur Negarigung dalam olahrasa. Berbeda dengan masyarakat Jawa Negarigung yang menganggap sangat penting kehalusan budi, maka masyarakat Jawa Mancanegari memberi kebebasan kepada individu untuk mengekspresikan diri (pikiran, perasaan, perilaku).

Kedua, keterikatan interpersonal etnis Minangkabau. Dalam perspektif adat Minangkabau, pandangan seorang pribadi terhadap yang lainnya hendaklah sama, walaupun seseorang itu mempunyai fungsi dan peranan yang berbeda. Etnis Minangkabau sangat mementingkan harmoni. Walaupun berbeda, mereka menyadari bahwa mereka saling dibutuhkan dan saling membutuhkan, sehingga terdapat kebersamaan. Dikatakan dalam ungkapan adat, "Nan buto pahambuih lasuang, nan pakak palapeh badie, nan lumpuah paunyi rumah, nan kuek pambaok baban, nan binguang kadisuruah-suruah, nan cadiak lawan barundiang." Hanya fungsi dan peranan seseorang itu berbeda dengan yang lain, tetapi sebagai manusia setiap orang itu hendaklah dihargai karena semuanya saling mengisi. Saling menghargai agar terdapat keharmonisan dalam pergaulan. Adat menggariskan,"nan tuo dihormati, samo gadang baok bakawan, nan ketek disayangi", yang berarti yang tua dihormati, sesama saling berkawan, yang mudah disayangi (Amir, 2011; Diradjo, 2015). Disini, nampak bahwa etnis Minangkabau sangat memperhatikan pendapat orang ketiga atau orang yang dituakan di luar dari relasi interpersonal.

Ketiga, keterikatan interpersonal etnis Madura. Etnis Madura memiliki keterikatan interpersonal yang khas. Wiyata (2002, 2013) menjelaskan adanya ungkapan yang terkenal pada orang Madura, "bhuppa' bhabbu' ghuru rato". Ungkapan ini menunjukkan prinsip kepatuhan orang Madura dengan urutan patuh kepada ayah ibu (orangtua), guru, dan pemerintah. Dalam kehidupan orang Madura terdapat standar referensi kepatuhan kepada figur-figur utama secara hierarkis. Durhakalah jika seorang anak tidak patuh kepada orangtuanya. Selanjutnya kepatuhan orang Madura kepada guru (termasuk ulama) lebih pada tataran moral dan masalah ukhrawi. Kepatuhan kepada pemimpin karena mereka telah sampai pada capaian melalui suatu usaha yang posisinya memang harus dipatuhi. Hal di atas menunjukkan bahwa etnis Madura punya keterikatan interpersonal yang khas.

Keempat, keterikatan interpersonal etnis Bugis-Makassar. Dalam tradisi Bugis-Makassar dikenal istilah pessé atau dalam versi lengkapnya pessé babua. Pessé merupakan konsep keberpihakan seorang Bugis-Makassar terhadap kondisi sulit yang dialami oleh orang lain. Konsep ini menunjukkan indikasi empati yang luar biasa terhadap tetangga, kerabat, atau kelompoknya akibat kondisi yang tidak menyenangkan, seperti kondisi serba kekurangan, terkena musibah atau suatu penyakit, berduka cita, dan sebagainya. Pessé dalam konteks masyarakat Bugis-Makassar terkait erat dengan identitas yang merupakan pengikat para anggota kelompok. Bagi seorang pelaut (yang menjadi identitas masyarakat Bugis-Makassar pada umumnya) atau seorang perantau di negeri seberang, konsep pessé menjadi identitas ke-Bugis-an dan ke-Makassar-an mereka, yang menjelaskan sempugi' sebagai sesama orang Bugis. Sebuah pepatah Bugis mengatakan, "iya sempugi'ku', rekkua de'na siri'na, engka messa pesséna", yang berarti "meski saudara-ku (sempugi'ku) sesama orang Bugis tidak menaruh siri' pada diriku, setidaknya dia masih menyisakan pessé". Dengan demikian dapat dipahami bahwa konsep pessé dalam masyarakat Bugis-Makassar adalah modalitas pemersatu yang penting. Konsep ini menjelaskan tentang kesiapan orang-orang yang memiliki keterikatan persaudaraan untuk saling membantu setiap saat jika diperlukan (Pelras, 2006).

Tujuan penelitian ini adalah mengetahui perbedaan keterikatan interpersonal antara beberapa suku yang ada di Indonesia, dalam hal ini etnis Jawa subkultur Negarigung, etnis Jawa subkultur Mancanegari, etnis Minangkabau, etnis Bugis-Makassar, dan etnis Madura. Adapun hipotesis yang diajukan adalah: ada perbedaan keterikatan interpersonal antara beberapa suku yang ada di 
Indonesia.

\section{Metode Penelitian}

Pendekatan yang dipakai dalam studi ini adalah pendekatan kuantitatif. Pendekatan kuantitatif digunakan dalam studi ini karena dua pertimbangan. Pertama, isu yang diangkat dalam studi ini dapat digunakan untuk menerangkan fenomena yang berlangsung pada masyarakat luas. Untuk itu diperlukan banyak subjek sebagai sampel penelitian. Kedua, studi ini membutuhkan adanya uji hipotesis. Uji hipotesis dilakukan untuk mengetahui perbedaan keterikatan interpersonal antar etnis di Indonesia, dalam hal ini adalah etnis Jawa subkultur Negarigung, etnis Jawa subkultur Mancanegari, etnis Minangkabau, etnis Bugis-Makassar, dan etnis Madura. Pengukuran terhadap variabel-variabel pene-litian didasarkan pada kondisi ex post facto. Maksudnya peneliti hanya mengukur aspek-aspek psikologis yang ada dalam diri subjek pada waktu tertentu (cross sectional study).

\section{Partisipan}

Responden penelitian skala ini adalah laki-laki dan perempuan, berusia 12 tahun hingga 72 tahun (remaja, dewasa awal, dewasa tengah, lansia). Pemilihan subjek dengan rentang yang panjang ini didasari pertimbangan bahwa setiap kelompok usia memiliki karakteristik keterikatan interpersonal yang berbeda-beda. Selain itu, pendidikan responden penelitian adalah Sekolah Dasar hingga Pascasarjana, warga Indonesia dengan etnis tertentu (Jawa subkultur Negarigung, Jawa subkultur Mancanegari, Madura, Minangkabau, Madura, Bugis-Makassar). Pengambilan sampel dilakukan dengan menggabungkan cluster random sampling dan stratified sampling. Yang pertama adalah penarikan sampel dari populasi yang dilakukan dengan cara random yang prinsipnya adalah semua populasi memperoleh kesempatan yang sama untuk menjadi sampel dengan mempertimbangkan klaster. Klaster sendiri adalah unit analisis yang mengandung unit analisis lain, dalam hal ini adalah dalam kota ada kecamatan, dalam kecamatan ada keluruhan, dalam kelurahan ada rukun warga, dalam rukun warga ada rukun tetangga. Sementara stratified sampling adalah teknik sampling di mana populasi digadi dalam beberapa subpopulasi yang diberi nama strata. Strata dalam penelitian ini meliputi remaja, dewasa awal, dewasa tengah, dan lansia (Jatnika, 2010). Dari proses sampling tersebut, diperoleh 1.420 subjek dengan rincian: etnis Jawa subkultur Negarigung yang tinggal di Kota Yogyakarta $(\mathrm{N}=478)$, subkultur Mancanegari yang tinggal di Surabaya dan sekitarnya $(\mathrm{N}=248)$, etnis Minangkabau yang tinggal di Padang dan sekitarnya $(\mathrm{N}=204)$, etnis Bugis-Makassar yang tinggal di Makassar dan sekitarnya $(\mathrm{N}=233)$, serta etnis Madura yang tinggal di Pulau Madura ( $\mathrm{N}=257)$.

\section{Prosedur dan Material}

Pengambilan data dilakukan pada responden dengan cara individual maupun klasikal. Cara klasikal dilakukan dengan mengundang responden dalam suasana kebersamaan yang fokus, seperti pertemuan dasawisma, pertemuan rukun tetangga, pertemuan dalam kelas, dan sebagainya. Cara individual dilakukan dengan mencari data dari rumah satu ke rumah lainya. Alat ukur yang digunakan dalam pengambilan data adalah Nashori Interpersonal Attachment Scale (Nashori, 2012). Beberapa contoh pernyataan adalah berikut ini: (1) "Janji sahabat saya untuk tidak mengulangi kesalahan yang sama membuat saya lebih percaya kepada sahabat saya" (aspek sikap dan perilaku mitra relasi). (2) "Saya dapat mengingat dengan baik semua kebaikan dari keluarga yang pernah bermasalah dengan saya" (aspek kualitas hubungan dengan mitra relasi). (3) "Dukungan dari orang yang saya hormati membuat saya bersemangat memperbaiki hubungan dengan orang yang berkonflik dengan saya" (aspek pertimbangan pihak ketiga kepada individu)

Validitas dan reliabilitas alat ukur diperoleh dengan mengujicobakan alat ukur. Uji coba alat ukur dilakukan oleh Nashori (2012) pada 55 orang responden yang berasal dari lokasi penelitian yang berasal dari berbagai etnis di Indonesia yang tinggal di Yogyakarta. Uji coba dilakukan pada 23 aitem pernyataan, sebanyak 17 di antaranya lolos dan 6 lainnya gugur. Pengukuran menggunakan batasan besar koefisien korelasi part-whole tiap-tiap butir untuk masing-masing skala yang digunakan,yaitu 0,30 (Idrus, 2009). Hasil pengukuran menunjukkan skala ini memiliki koefisien korelasi aitem-total 0,329-0,757. Batasan besar koefisien alpha menggunakan pandangan Kline (2005) yang mengelompokkan batasan koefisien reliabilitas menjadi tiga, yaitu reliabilitas dengan nilai sekitar 0,9 disebut excellent, nilai sekitar 0,8 disebut very good, dan nilai sekitar 0,70 disebut adequate. Hasil pengukuran menunjukkan bahwa koefisien alpha subskala persepsi terhadap sikap dan perilaku mitra relasi adalah 0.933, subskala kualitas hunungan dengan mitra relasi 0.896 dan subskala pertimbangan pihak ketiga adalah 0.924 .

Setelah data dikumpulkan dan diinput, dilakukan analisis data.

\section{Teknik Analisis}

Teknik analisis data yang digunakan dalam penelitian ini adalah analisis varians (Anova). Anova adalah suatu teknik analisis data yang dimaksudkan untuk menguji perbedaan dari tiga kelompok atau lebih (Herawati \& Edi, 2016)). Kelompok-kelompok yang hendak diukur perbedaannya adalah Jawa subkultur mancanegari, Jawa subkultur negarigung, Minangkabau, Madura, Bugis-Makassar).

Teknik ini digunakan untuk mengetahui; (a) perbedaan keterikatan interpersonal secara umum antara etnis Jawa subkultur Negarigung, etnis Jawa 
subkultur Mancanegari, etnis Minangkabau, etnis Madura, dan etnis Bugis-Makassar; (b) perbedaan dimensi persepsi sikap dan perilaku mitra relasi pada lima kelompok etnis; (c) perbedaan dimensi kualitas hubungan antara individu dan mitra relasi pada lima kelompok etnis; dan (d) perbedaan dimensi pertimbangan dari pihak ketiga terhadap individu pada lima kelompok etnis .

Setelah dilakukan analisis Anova, penelitian ini juga menggunakan teknik analisis post-hoc analysis dari ANOVA. Post-hoc analysis dimaksudkan untuk mengetahui perbedaan keterikatan interpersonal masing-masing suku. Adapun kriteria pengam-bilan keputusan adalah dengan melihat tabel Homogenety of Variances Test. Ketentuannya adalah sebagai berikut (1) Jika signifikansi > 0,05 maka dikatakan bahwa varian sama, (2) Jika signifikansi $<0,05$ maka dikatakan bahwa varian tidak sama. Oleh karena itu, jika varian sama, maka pada tabel post hoc, hasil analisis dilihat pada Bonferroni. Selanjutnya, jika varian tidak sama, maka pada tabel post hoc, hasil analisis dilihat pada GomesHowell (Herawati \& Edi, 2016).

\section{Hasil Penelitian}

\section{Hasil Analisis Deskriptif}

Hasil analisis deskriptif tabel 1 di atas menunjukkan bahwa nilai minimum adalah 4 dan nilai maksimum adalah 20. Adapun urutan rerata skor dimensi sikap dan perilaku terhadap mitra variabel keterikatan interpersonal adalah (1) etnis Jawa subkultur Negarigung, (2) etnis Jawa subkultur Mancanegari, (3) etnis Madura, (4) etnis Bugis-Makassar, dan (5) etnis Minangkabau.

Kemudian, hasil analisis deskriptif tabel 2 menunjukkan bahwa nilai minimum adalah 5 dan nilai maksimum adalah 20. Adapun urutan rerata skor keterikatan interpersonal adalah (1) etnis Jawa subkultur Mancanegari, (2) etnis Minangkabau, (3) etnis Bugis-Makassar, (4) etnis Madura, serta (5) etnis Jawa subkultur Negarigung.

Sementara itu hasil analisis deskriptif tabel 3 menunjukkan bahwa nilai minimum adalah 0 dan nilai maksimum adalah 20. Adapun urutan rerata skor keterikatan interpersonal adalah (1) etnis Minangkabau, (2) etnis Jawa subkultur Negarigung, (3) etnis Jawa subkultur Mancanegari, (4) etnis Madura, serta (5) etnis Bugis-Makassar.

\section{Uji Hipotesis}

Dalam penelitian ini, dilakukan uji hipotesis terhadap empat hipotesis penelitian. Analisis data dilakukan dengan Anova (Herawati \& Edi, 2016). Hasil analisis dapat dilihat dari Tabel 5 di bawah ini.

Tabel 1. Hasil uji deskriptif dimensi sikap dan perilaku terhadap mitra relasi

\begin{tabular}{lllll}
\hline Etnis & N & Mean & Minimum & Maximum \\
\hline Jawa Negarigung & 478 & 13,20 & 6 & 20 \\
Jawa Mancanegari & 248 & 12,83 & 4 & 19 \\
Madura & 257 & 12,38 & 6 & 18 \\
Bugis-Makassar & 233 & 12,34 & 8 & 17 \\
Minangkabau & 204 & 11,88 & 7 & 17 \\
\hline Total & 1420 & 12,66 & 4 & 20 \\
\hline
\end{tabular}

Tabel 2. Hasil Uji deskripsi dimensi kualitas hubungan dengan mitra relasi

\begin{tabular}{lllll}
\hline Etnis & N & Mean & Minimum & Maximum \\
\hline Jawa Mancanegari & 248 & 15,02 & 8 & 20 \\
Minangkabau & 204 & 15,00 & 9 & 19 \\
Bugis-Makassar & 233 & 14,36 & 5 & 20 \\
Madura & 257 & 14,07 & 6 & 20 \\
Jawa Negarigung & 478 & 13,58 & 7 & 20 \\
\hline Total & 1420 & 14,25 & 5 & 20 \\
\hline
\end{tabular}

Tabel 3. Hasil uji deskriptif pertimbangan pihak ketiga terhadap individu

\begin{tabular}{lllll}
\hline Etnis & N & Mean & Minimum & Maximum \\
\hline Minangkabau & 204 & 15,6716 & 7 & 20 \\
Jawa Negarigung & 478 & 15,1276 & 7 & 20 \\
Jawa Mancanegari & 248 & 13,8790 & 9 & 19 \\
Madura & 257 & 13,8677 & 0 & 20 \\
Bugis-Makassar & 233 & 13,7811 & 8 & 20 \\
\hline Total & 1420 & 14,5387 & 0 & 20 \\
\hline
\end{tabular}


Analisis Anova dimaksudkan untuk menguji hipotesis yang berbunyi bahwa ada perbedaan keterikatan interpersonal antara etnis Jawa subkultur Negarigung, etnis Jawa subkultur Mancanegari, etnis Minangkabau, etnis Madura, dan etnis BugisMakassar. Berdasarkan tabel 4, nilai signifikansi pada uji Anova menunjukkan $\mathrm{F}=11,773$ dan $\mathrm{p}=0,000(\mathrm{p}<$ $0,05)$, yang berarti hipotesis diterima. Oleh karena itu dapat disimpulkan bahwa ada perbedaan keterikatan interpersonal antar etnis dengan urutan (1) etnis Minangkabau (M=42,55), (2) Jawa Negarigung $(M=41,91),(3)$ etnis Jawa Mancanegari $(M=41,73)$, (4) etnis Bugis-Makassar (M=40,48), (4) etnis Madura $(\mathrm{M}=40,32)$.
Selanjutnya, perlu dilakukan analisis post hoc pada variabel keterikatan interpersonal. Table post hoc di atas memperlihatkan bahwa ada perbedaan keterikatan interpersonal pada kelompok-kelompok suku. Tabel homogeneity menunjukkan signifikansi $0,002(<0,05)$. Dengan kata lain, varians tidak sama. Selanjutnya, jika varians tidak sama, maka hasil analisis yang dilihat adalah Gomes-Howell. Karenanya, table post hoc di atas dilihat pada hasil analisis Gomes-Howell.

Tabel 4. Hasil Uji Hipotesis

\begin{tabular}{llll}
\hline No & Hipotesis & $\boldsymbol{F}$ & $\boldsymbol{p}$ \\
\hline 1 & Sikap dan perilaku mitra relasi & 18,640 &, 000 \\
2 & Kualitas hubungan dengan mitra relasi & 26,436 &, 000 \\
3 & Pertimbangan pihak ketiga terhadap individu & 42,576 &, 000 \\
\hline
\end{tabular}

\section{Catatan: $F=$ skor Anova, $p=p$-value}

Tabel 5. Hasil analisis post-hoc pada dimensi sikap dan perilaku (Games-Howell)

\begin{tabular}{llllll}
\hline No & (I) SUKU & (J) SUKU & Perbedaan rerata & $p$ & Kesimpulan \\
\hline 1 & Jawa-Mancanegari & Madura & .449 & .096 & Tidak ada perbedaan \\
2 & & Minang & .948 & .000 & Ada perbedaan \\
3 & & Jawa-Negarigung & -.372 & .235 & Tidak ada perbedaan \\
4 & & Bugis-Makassar & .487 & .053 & Tidak ada perbedaan \\
5 & \multirow{2}{*}{ Madura } & Minang & .499 & .033 & Ada perbedaan \\
6 & & Jawa-Negarigung & -.822 & .000 & Ada perbedaan \\
7 & & Bugis-Makassar & .038 & .999 & Tidak ada perbedaan \\
8 & \multirow{2}{*}{ Minang } & Jawa-Negarigung & -1.321 & .000 & Ada perbedaan \\
9 & & Bugis-Makassar & -.461 & .056 & Tidak ada perbedaan \\
10 & Jawa-Negarigung & Bugis-Makassar & .860 & .000 & Ada perbedaan \\
\hline
\end{tabular}

Tabel 6. Hasil analisis post-hoc pada dimensi kualitas hubungan (Games-Howell)

\begin{tabular}{llllll}
\hline No & (I) SUKU & (J) SUKU & Perbedaan rerata & $p$ & \\
\hline 1 & Jawa-Mancanegari & Madura & .950 & .000 & Ada perbedaan \\
2 & & Minang & .029 & 1.000 & Tidak ada perbedaan \\
3 & & Jawa-Negarigung & 1.441 & .000 & Ada perbedaan \\
4 & & Bugis-Makassar & .668 & .007 & Ada perbedaan \\
5 & \multirow{2}{*}{ Madura } & Minang & -.921 & .000 & Ada perbedaan \\
6 & & Jawa-Negarigung & .490 & .061 & Tidak ada perbedaan \\
7 & & Bugis-Makassar & -.282 & .678 & Tidak ada perbedaan \\
8 & Minang & Jawa-Negarigung & 1.411 & .000 & Ada perbedaan \\
9 & & Bugis-Makassar & .639 & .011 & Ada perbedaan \\
10 & Jawa-Negarigung & Bugis-Makassar & -.773 & .000 & Ada perbedaan \\
\hline
\end{tabular}

Tabel 7. Hasil analisis post-hoc pada dimensi pertimbangan pihak ketiga (Games-Howell)

\begin{tabular}{llllll}
\hline No & (I) SUKU & (J) SUKU & Perbedaan rerata & $p$ & Kesimpulan \\
\hline 1 & Jawa-Mancanegari & Madura & .011 & 1.000 & Tidak ada perbedaan \\
2 & & Minang & -1.793 & .000 & Ada perbedaan \\
3 & & Jawa-Negarigung & -1.249 & .000 & Ada perbedaan \\
4 & & Bugis-Makassar & .098 & .979 & Tidak ada perbedaan \\
5 & Madura & Minang & -1.804 & .000 & Ada perbedaan \\
6 & & Jawa-Negarigung & $-1.260 *$ & .000 & Ada perbedaan \\
\hline
\end{tabular}




\begin{tabular}{llllll}
\hline 7 & Bugis-Makassar & .087 & .991 & Tidak ada perbedaan \\
8 & Minang & Jawa-Negarigung & .544 & .041 & Ada perbedaan \\
9 & & Bugis-Makassar & 1.890 & .000 & Ada perbedaan \\
10 & Jawa-Negarigung & Bugis-Makassar & 1.346 & .000 & Ada perbedaan \\
\hline
\end{tabular}

Hasil analisis post-hoc lengkap dapat dilihat di Tabel 5, Tabel 6, dan Tabel 7. Ditemukan bahwa Etnis Jawa Nagarigung cenderung lebih tinggi dalam dimensi rasa percaya terhadap sikap dan perilaku mitra relasi dibanding etnis-etnis lainnya kecuali etnis Jawa Mancanegari. Sementara itu etnis Jawa Mancanegari cenderung lebih tinggi dalam persepsi kualitas hubungan dengan mitra relasi dibanding seluruh etnis lainnya kecuali etnis Minangkabau. Untuk dimensi kuatnya pertimbangan pihak ketiga dalam relasi, etnis Minangkabau cenderung lebih tinggi dibanding seluruh etnis lain.

\section{Diskusi}

Penelitian ini bertujuan untuk mengetahui perbedaan keterikatan interpersonal antara etnis Jawa subkultur Negarigung, etnis Jawa subkultur Mancanegari, etnis Minangkabau, etnis Madura, serta etnis BugisMakassar. Hasil penelitian secara umum menunjukkan bahwa (1) ada perbedaan keterikatan interpersonal antar etnis. Hasil lainnya menunjukkan bahwa ada perbedaan dimensi persepsi terhadap sikap dan perilaku mitra relasi masing-masing antara etnis dengan Jawa subkultur Negarigung sebagai pemilik skor tertinggi untuk dimensi ini. Di samping itu ada perbedaan dimensi kualitas hubungan dengan mitra relasi. Jawa subkultur Manca-negari meraih skor tertinggi untuk dimensi ini. Kemudian, ada perbedaan dimensi pertimbangan pihak ketiga terhadap individu antara etnis dengan etnis Minangkabau sebagai pemilik skor tertinggi.

Singelis, Triandis, Bhawuk, dan Gelfand (1995) mengungkap bahwa budaya kolektivistik ditandai oleh orang-orang yang ada dalam suatu kelompok saling tergantung, memandang diri sebagai bagian tak terpisahkan dari suatu kelompok, menjadikan tujuan kelompok sebagai prioritas, mementingkan norma kelompok daripada kepentingan pribadi. Sementara budaya individualistik merupakan suatu budaya yang berakar pada pandangan bahwa individu tidak terikat dan bebas terhadap individu yang lain, mementingkan tujuan individu daripada tujuan bersama, sikap individu secara pribadi lebih menentukan daripada mengikuti aturan.

Masyarakat yang memiliki budaya kolektivisme melahirkan individu-individu yang memiliki keterikatan interpersonal yang tinggi. Keterikatan interpersonal sendiri, sebagaimana diungkapkan Nashori (2011), adalah suatu kondisi psikologis saat individu sangat mempertimbangkan keberadaan orang lain dalam pengambilan keputusan atas hal-hal yang penting dalam kehidupannya, khususnya yang berkaitan dengan relasi interpersonal dengan orang lain. Semua etnis di Indonesia, termasuk etnis Jawa subkultur Negarigung, etnis Jawa subkultur Mancanegari, etnis Minangkabau, etnis Madura, serta etnis BugisMakassar memiliki budaya kolektivisme. Mereka memandang diri sebagai bagian tak terpisahkan dari kelompoknya. Keterikatan interpersonal yang tinggi lahir dari masyarakat yang memiliki budaya kolektivitisme yang tinggi. Sekalipun mereka pada dasarnya memiliki budaya kolektivistik, namun mereka memiliki nilai hidup yang secara relatif berbeda. Berikut ini penjelasannya.

\section{Nilai Keterikatan Interpersonal Etnis Minangkabau}

Hasil penelitian ini menunjukkan bahwa etnis Minangkabau memiliki keterikatan interpersonal dimensi pertimbangan pihak ketiga paling unggul dibanding etnis-etnis lain. Dalam tradisi Minangkabau, terdapat tiga pilar yang menopang keutuhan budaya serta adat istiadat, yaitu para alim ulama, cerdik pandai, dan ninik mamak yang dikenal dengan Tungku Tigo Sajarangan. Dalam praktiknya, ketiga pilar tersebut bersifat saling melengkapi dan saling mendukung dalam posisi yang sama tingginya. Seluruh perkara atau masalah dalam masyarakat Minang yang dikenal demokratis dan egaliter diselesaikan secara mufakat melalui musyawarah yang mempertemukan ketiga pilar tersebut (Amir, 2011; Diradjo, 2015). Individu mengikatkan diri dengan keputusan kelompok maupun orang-orang yang termasuk pilar di atas.

Orang-orang Minangkabau memberi kedudukan yang istimewa bagi kaum perempuan, yang diberi julukan Bundo Kanduang. Bundo kanduang berperan dalam menentukan keberhasilan pelaksanaan kesepakatan-kesepakatan yang telah dirumus-kan oleh pihak laki-laki, dalam posisi mereka sebagai mamak (paman atau saudara dari pihak ibu), dan penghulu (kepala suku). Pengaruh yang dimilikinya menjadikan perempuan dalam etnis Minangkabau disimbolisasi sebagai Limpapeh Rumah Nan Gadang (pilar utama rumah) (Amir, 2011; Diradjo, 2015). Ini menunjukkan bahwa peran publik bisa mengintervensi relasi antar individu.

\section{Keterikatan Etnis Jawa Subkultur Negarigung}

Hasil penelitian ini menunjukkan bahwa etnis Jawa subkultur Negarigung memiliki keterikatan interpersonal dengan urutan kedua, dimensi persepsi terhadap sikap dan perilaku mitra relasi pada urutan pertama, dimensi pertimbangan pihak ketiga 
terhadap individu pada urutan kedua, dan dimensi kualitas hubungan dengan mitra relasi ada pada urutan kelima.

Etnis Jawa, dalam hal ini yang bersubkultur Negarigung, sangat mementingkan nilai budaya yang mementingkan prinsip rukun (harmony). Dengan prinsip rukun tersebut individu etnis Jawa akan berupaya agar hubungan dengan orang lain, termasuk orang yang berperilaku tidak menyenangkan atau menyakitkan terhadapnya, tetap berjalan normal. Etnis Jawa belajar dan membiasakan diri menggunakan olah rasa (olah roso) sehingga mereka peka dengan sikap dan perilaku orang lain yang menunjukkan perubahan diri menjadi lebih baik dan menunjukkan komitmen untuk tidak melakukan perbuatan yang tidak menyenangkan di masa lalu (Nashori, dkk., 2019).

Nilai rukun ini diterapkan individu dalam berbagai konteks. Hasil penelitian Dewi (2005) menunjukkan bahwa ekspresi emosi tidak berlebihan yang ditunjukkan oleh orang Jawa adalah wujud penghormatan kepada sesama, tenggang rasa dan ekspresi ramah tamah untuk menjaga kenyamanan perasaan orang lain. Ekspresi emosi pada orang Jawa juga cenderung dikontrol dengan ketat, agar tidak ditunjukkan secara berlebihan baik di rumah sendiri maupun di lingkungan sosial pada umumnya. Mulder (1996) menunjukkan bahwa prinsip kerukunan dimaksudkan untuk mempertahankan masyarakat dalam keadaan yang harmonis. Rukun dapat juga berarti "dalam keadaan selaras", "tenang dan tentram", "tanpa perselisihan dan pertentangan", serta "bersatu dalam maksud untuk saling membantu".

Masih berkait dengan nilai rukun, masyarakat dalam kultur Jawa dikenal dengan tradisi gotong royong. Beberapa falsafah hidup yang melekat pada kultur Jawa seperti, "saiyeg saekopraya gotong royong"; "hapanjang hapunjung hapasir-wukir loh jinawi, tata tentrem kertaraharja", menjelaskan bagaimana prinsip hidup saling membantu benarbenar mengalir dalam kehidupan masyarakat Jawa. Orang Jawa menganggap diri mereka bukan hanya sekadar kumpulan individu, tapi merupakan satu kesatuan wujud "satu untuk semua dan semua untuk satu". "Mangan ora mangan sing penting ngumpul" (makan atau tidak makan, yang penting berkumpul) juga merupakan salah satu semboyan hidup masyarakat Jawa, yang kian mempertegas tradisi selalu ingin bersama dengan lingkungan sosialnya (Wijayanti \& Nurwianti, 2010),

\section{Keterikatan Interpersonal Jawa Subkultur Mancanegari}

Dari penelitian ini diketahui bahwa etnis Jawa subkultur Mancanegari memiliki skor dimensi kualitas hubungan dengan mitra relasi berada pada urutan pertama atau yang tertinggi. Sama seperti etnis Jawa subkultur Negarigung, etnis Jawa subkultur Mancanegari juga memegang prinsip harmony atau kerukunan. Selain itu, ciri masyarakat Jawa subkultur Mancanegari yang menonjol adalah sangat terbuka atau terus suka berterus terang (ekspresif) serta lebih akrab satu sama lain (Sutarto, 2004). Hal ini menjadikan mereka agak berbeda dengan etnis Jawa subkultur Negarigung dalam olah rasa. Etnis Jawa subkultur Mancanegari tetap menggunakan olah rasa dalam memperhatikan perubahan sikap dan perilaku orang lain, namun tidak sekuat Jawa Negarigung.

Adapun hal yang lebih menonjol adalah mereka menganggap sangat penting kualitas hubungan dengan mitra relasi di masa lalu dan komitmen relasi di masa depan sebagai sesuatu yang penting dalam pergaulan sosial. Karenanya mereka cenderung tidak menyimpan rasa sakit hati akibat masalah dalam pergaulan sosial (Nashori, dkk., 2019). Jotakan atau neng-nengan (diamdiaman/tidak saling bersapaan) yang dikenal pada etnis Jawa subkultur Negarigung adalah perilaku yang tidak populer pada masyarakat Jawa subkultur Mancanegari.

Keterbukaan dan keterusterangan banyak memberi sumbangan terhadap terjadinya keakraban yang menunjukkan etnis Jawa subkultur Mancanegari mengembangkan dimensi kualitas hubungan dengan mitra relasi.

\section{Keterikatan Interpersonal Etnis Bugis-Makassar}

Hasil penelitian ini menunjukkan bahwa etnis BugisMakassar memiliki keterikatan intepersonal dengan urutan keempat. Selanjutnya, mereka memiliki dimensi persepsi terhadap sikap dan perilaku mitra relasi pada urutan keempat, dimensi kualitas hubungan dengan mitra relasi pada urutan ketiga, dimensi pertimbangan pihak ketiga pada urutan kelima.

Dalam tradisi Bugis-Makassar juga dikenal istilah pessé, atau pessé babua dalam versi lengkapnya. Pessé merupakan konsep keberpihakan seorang Bugis-Makassar terhadap kondisi sulit yang dialami oleh orang lain. Pessě merupakan representasi dari sebuah sikap yang dapat merasakan penderitaan sesama manusia, dan tentu saja sikap ini akan senantiasa memunculkan solidaritas bagi sesama manusia. Berpegang teguh pada prinsip kehidupan yang mampu merasakan penderitaan sesama manusia, dapat memicu dorongan atau keinginan untuk senantiasa mengulurkan tangan memberi pertolongan bagi mereka yang membutuhkannya. Konsep ini menunjukkan indikasi empati yang luar biasa terhadap tetangga, kerabat, atau kelompoknya akibat kondisi yang tidak menyenangkan, seperti kondisi serba kekurangan, terkena musibah atau suatu penyakit, berduka cita, dan sebagainya.

Pessé dalam konteks masyarakat BugisMakassar terkait erat dengan identitas yang merupakan pengikat para anggota kelompok. Bagi seorang pelaut (yang menjadi identitas masyarakat Bugis pada umumnya) atau seorang perantau di negeri seberang, konsep pessé menjadi identitas keBugis-an mereka, yang menjelaskan sempugi' sebagai 
sesama orang Bugis. Sebuah pepatah Bugis mengatakan, "iya sempugi'ku', rekkua de'na siri'na, engka messa pesséna", yang berarti, "meski saudara$\mathrm{ku}$ (sempugi'ku) sesama orang Bugis tidak menaruh siri' pada diriku, setidaknya dia masih menyisakan pessé". Dengan demikian, dapat dipahami bahwa konsep pessé dalam masyarakat Bugis-Makassar adalah modalitas pemersatu yang penting. Konsep ini menjelaskan tentang kesiapan orang-orang yang memiliki keterikatan persaudaraan untuk saling membantu setiap saat jika diperlukan (Pelras, 2006).

Tradisi lain yang menunjukkan pentingnya keterikatan interpersonal adalah siri'. Prinsip ini mengajarkan bahwa orang Bugis-Makassar sangat menjunjung tinggi persoalan siri' atau rasa malu. Orang Bugis-Makassar akan senantiasa merasa malu untuk melakukan perbuatan yang tidak baik. Karenanya, pantang untuk melakukan perbuatan memalukan yang bertentangan dengan norma agama (sara'), hukum maupun norma adat dan kesopanan (pangngaderreng). Adalah sebuah aib yang memalukan bila dikemudian hari terbukti melakukan hal-hal yang dianggap sebagai perbuatan tidak terpuji. Harga diri atau integritas merupakan barang/ mata uang yang paling berharga bagi orang BugisMakassar. Kehilangan harga diri bagi orang BugisMakassar laksana kehilangan segala-galanya. Lebih baik kehilangan uang dari pada harga diri, karena kehilangan uang sejatinya hanya kehilangaan sedikit, akan tetapi kehilangan integritas maka sesungguhnya manusia telah kehilangan segala-galanya.

\section{Keterikatan Interpersonal Etnis Madura}

Terakhir, ditunjukkan bahwa etnis Madura memiliki dimensi persepsi terhadap sikap dan perilaku mitra relasi pada urutan ketiga, dimensi kualitas hubungan dengan mitra relasi pada urutan keempat, dimensi pertimbangan pihak ketiga pada urutan keempat.

Keterikatan interpersonal pada etnis Madura terkait dengan sejumlah karakteristik yang dimilikinya. Beberapa karakteristik etnis Madura terkait dengan keterikatan interpersonal adalah sebagai berikut: (a) kesadaran untuk saling membina persaudaraan; (b) ramah tamah dan saling menghormati; (c) solidaritas yang tinggi; (d) pengertian dan toleransi; (e) berpegang teguh pada prinsip "lebih baik putih tulang daripada putih mata"; (f) terbuka tapi tetap mempertahankan gengsi kehormatan (Rifai, 2007). Empat karakteristik pertama, yaitu kesadaran untuk saling membina persaudaraan, ramah tamah dan saling menghormati, solidaritas yang tinggi, serta pengertian dan toleransi, menunjukkan budaya kolektivistik pada etnis Madura sekaligus menunjukkan arti penting kehadiran orang lain bagi etnis Madura. Modal-modal tersebut menunjukkan arti penting orang lain bagi individuindividu etnis Madura. Empat karakteristik pertama menunjukkan bahwa etnis Madura sangat menghargai orang lain.

Salah satu prinsip yang dihargai etnis Madura adalah penghormatan akan harga diri. Harga diri setiap orang harus dijunjung tinggi. Sedemikian pentingnya harga diri itu, mereka mengembangkan karakteristik yang kelima dan keenam. Mereka berpegang teguh pada prinsip "ango'an poteya tolang etembang poteya mata" yang secara harfiah berarti "lebih baik putih tulang daripada putih mata". Maksud dari kalimat ini, menurut Wiyata (2002, 2013) adalah lebih baik mati (putih tulang) daripada menanggung malu (putih mata). Secara implisit dapat dipahami bahwa etnis Madura memandang sangat penting harga diri. Harga diri harus dijaga dengan sebaik-baiknya.

Salah satu tradisi yang dihidupkan etnis Madura berkaitan dengan pemeliharaan harga diri adalah carok. Oleh etnis Madura, anak perempuan dianggap prestise bagi orangtua atau keluarganya. Menjadi simbol prestise bagi keluarga maupun lakilaki, perempuan secara kultural dituntut untuk menjunjung tinggi kesopanan, menjaga diri dari pergaulan bebas terutama dengan lawan jenis, mampu membawa diri terutama ketika bergaul dengan orang yang lebih tua, bahkan sampai pada urusan cara berpakaian. Sedemikian berartinya kaum perempuan dalam tradisi Madura, sehingga konflik seringkali muncul akibat adanya gangguan yang menimpa seorang perempuan dari laki-laki lain. Tradisi carok yang hidup dalam masyarakat Madura ditengarai seringkali bermula dari kasus perempuan. Dalam konteks ini, pepatah yang begitu lekat pada masyarakat Madura "ango'an poteya tolang etembang poteya mata" (lebih baik putih tulang atau mati daripada putih mata atau tidak dapat melihat atau kehormatannya terlepas) relevan untuk digunakan untuk memahami pentingnya harga diri (Mardhatillah, 2014).

Ada pandangan hidup yang berkembang pada etnis Madura yang menjadikan keterikatan interpersonal mereka mengalami penurunan. Ada sebuah peribahasanya yang berbunyi "mon erek tarek semma'. Sekalipun orang Madura bersifat individualistis, sehingga kepentingan pribadinya selalu bakal didahulukan dan diutamakannya, namun semangat kekeluargaan mereka terhitung besar. Pertalian antar kerabat sangat diperhatikan oleh orang Madura, terutama bila dihadapkan pada situasi yang mempertentangkan kelompok dirinya dengan komunitas di luarnya. Mereka percaya bahwa memiliki kerabat dan keluarga yang besar jumlahnya merupakan tanda keberhasilan dalam hidup di dunia ini (Rifai, 2007). Oleh karena itu, tidak jarang oreng daddhi taretan (orang lain bisa menjadi saudara meskipun tidak memiliki hubungan darah) ketika hubungan interpersonal terjalin dengan baik.

Meski demikian, walau suku Madura dan Bugis-Makassar memiliki banyak nilai kolektivistik dan menekankan relasi interpersonal, namun bila dibandingkan tiga suku lainnya relatif masih lebih rendah dalam setiap dimensi. Artinya, dibanding suku-suku lainnya, Bugis-Makassar lebih tidak menekankan pada kepercayaan terhadap sikap dan perilaku mitra dan pertimbangan pihak ketiga. Akan 
tetapi suku ini masih lebih tinggi dibandingkan Jawa Nagarigung dalam aspek penekanan pada kualitas hubungan. Sementara itu Madura lebih tidak menekankan pada kualitas hubungan dengan mitra serta pertimbangan pihak ketiga. Namun, mereka lebih tinggi dibanding Minangkabau dalam kepercayaan terhadap sikap dan perilaku mitra.

\section{Kesimpulan}

Keterikatan interpersonal individu sangat besar pengaruhnya terhadap kualitas hubungan individu dengan orang lain, kesediaan memaafkan orang lain, dan imbasnya juga kepada kualitas diri individu. Fenomena keterikatan interpersonal ini tampak menonjol pada etnis-etnis di Indonesia. Dari penelitian yang dilakukan terhadap beberapa etnis di Indonesia ditemukan sejumlah temuan penting. Hasil penelitian menunjukkan bahwa ada perbedaan keterikatan interpersonal antar etnis besar di Indonesia dengan urutan etnis Minangkabau, etnis Jawa subkultur Negarigung, etnis Jawa subkultur Mancanegari, etnis Bugis-Makassar, dan etnis Madura. Dalam hal sikap dan perilaku positif dengan mitra relasi, etnis Jawa subkultur Nagarigung dan etnis Jawa subkultur Negarigung cenderung lebih menonjol dibanding etnis-etnis lain. Dalam hal persepsi tentang kualitas hubungan dengan mitra relasi, etnis Jawa Mancanegari dan etnis Minangkabau cenderung lebih menonjol dalam persepsi kualitas hubungan dengan mitra relasi. Khusus terkaitan dengan pertimbangan pihak ketiga dala relasi, etnis Minangkabau cenderung lebih tinggi dibanding seluruh etnis lain.

\section{Keterbatasan dan Saran}

Studi ini dilakukan pada lima kelompok etnis, padahal etnis di Indonesia berjumlah lebih dari $400 \mathrm{suku}$ bangsa. Karenanya, hasil penelitian belum mencerminkan keterikatan interpersonal semua atau sebagian suku bangsa yang ada di Negara Kesatuan Republik Indonesia. Pemilihan etnis yang ada di Indonesia belum melibatkan suku-suku penting lain di Indonesia, seperti Aceh, Melayu, Sunda, Banjar, Dayak, Lombok, dan sebagainya.

Peneliti menyarankan agar penelitian ini dapat juga dilakukan pada lebih banyak suku bangsa di Indonesia, terutama suku-suku yang memiliki populasi besar seperti Sunda, Batak, Melayu, Betawi, Bugis, Dayak, Bali, Sasak, dan sebagainya. Selain itu, peneliti berikutnya disarankan untuk melakukan perbaikan atas alat ukur penelitian sehingga validitas dan reliabilitasnya meningkat atau optimal.

\section{Daftar Pustaka}

Amir, M. S. (2011). Masyarakat adat Minangkabau. Jakarta: Citra Harta Prima.

Calmes, C. A. \& Roberts, J. E. (2008). Rumination in interpersonal relationships: Does corumination explain gender differences in emotional distress and relationship satisfaction among college students?. Cognitive Therapy and Research, 32(4), 577-590. doi: 10.1007/s10608-008-9200-3

den Brok, P., Wubbels, T., Veldman, I., \& van Tartwijk, J. (2009). Perceived teacher-student interpersonal relationships in Dutch multiethnic classesournal. Educational Research and Evaluation, 15(2), 119-135. doi: $10.1080 / 13803610902784303$

Dewi, L. Z. (2005). Pengalaman, ekspresi, dan kontrol marah pada orang Batak dan Jawa. Jurnal Psikologi Fakultas Psikologi UNIKA Atma Jaya, 16(2).

Diradjo, I. D. S. (2015). Tambo Alam Minangkabau. Bukittinggi: Penerbit Kristal Multimedia.

Downie, M., Mageau, G. A., \& Koestner, R. (2008). What makes for a pleasant social interaction? Motivational dynamics of interpersonal relations. The Journal of Social Psychology. 148 (5). 523-534. doi: 10.3200/SOCP.148.5.523534

Herawati, N. \& Edi, F. R. A. (2016). Aplikasi komputer untuk psikologi. Malang: AE Publishing.

Hoorens, V. \& Poortinga, Y.H. (2000). Behavior in social context. In K. Pawlik \& M.R. Rosenzweig (eds.), International handbook of psychology (p.40-53). Sage Publications Ltd. https://doi.org/10.4135/9781848608399.n3

Idrus, M. (2009). Metode penelitian ilmu sosial Edisi Kedua. Jakarta: Penerbit Erlangga.

Jatnika, R. (2010). Sampling: Bahan kuliah Statistik Program Doktor Psikologi. Bandung: Fakultas Psikologi Unpad.

Kline, R. B. (2005). Principle and practice of structural equation modeling ( 2 nd Ed.). New York: The Guilford Press.

Koentjaraningrat. (1994). Kebudayaan Jawa. Jakarta: PN Balai Pustaka.

Kurtz, J. E. \& Sherker, J. L. (2003). Relationship quality, trait similarity, and self-other agreement on personality ratings in college roommates. Journal of Personality,71(1), 21-48. doi: 10.1111/1467-6494.t01-1-00005

Li, R., Jiang, T., Yong, J., \& Zhou, H. (2018). College students' interpersonal relationship and empathy level predict internet altruistic behavior-empathy level and online social support as mediators. Psychology and behavioral sciences, 7(1) 1-7. 10.11648/j.pbs.20180701.11

Mardhatillah, M. (2014). Perempuan Madura sebagai simbol prestise dan pelaku tradisi perjodohan. Musawa Jurnal Studi Gender dan Islam, 13(2), 167-178.doi: 10.14421/musawa.2014.132.167-178

McCullough, M. E., Worthington, E. L., Rachal, K. C., Sandage, S. J., Brown, S. W., \& Hight, T. L. (1998). Interpersonal forgiving in close relationships II: Theoretical elaboration and measurement. Journal of Personality and Social 
Psychology, 75(6), 1586-1603. doi: 10.1037\%2F0022-3514.75.6.1586

Mulder, N. (1996). Pribadi dan Masyarakat Jawa. Jakarta: Pustaka Sinar Harapan.

Naim, M. (1979). Merantau: Pola migrasi suku Minangkabau. Yogyakarta: Gadjah Mada University Press

Nashori, H. F. (2011). Keterikatan interpersonal, trait kepribadian, dan pemaafan: Sebuah tinjauan teoritik. Jurnal Psikologi (UIN Sunan Kalijaga), 4(2), 04-126. Diunduh dari http://download.garuda.ristekdikti.go.id/arti cle.php? article $=397741 \&$ val $=8722 \&$ title $=$ KET ERIKATAN\%20INTERPERSONAL\%20TRAIT \%20KEPRIBADIAN\%20DAN\%20PEMAAFAN $\% 20$ SEBUAH\%20KAJIAN\%20TEORITIK

Nashori, H.F, Iskandar, T.Z., Setiono, K., \& Siswadi, A.G.P. (2011). Forgiveness among muslim student university. The roles of islamic psychology in the effort of increasing life quality: Proceeding International Conference on Islamic Psychology and the Third of Congress of Association of Islamic Psychology. Malang: Faculty of Psychology, State Islamic University Malang

Nashori, H.F. (2012). Pemaafan pada etnis Jawa warga Kota Yogyakarta. Disertasi. Bandung: Universitas Padjadjaran.

Nashori, H.F., Wijaya, H.E., Diana, R.R., \& Herawati, N. (2019). Forgiveness among Maduranese ethnic: The relation beetween religiousity, interpersonal attachment, and personality trait. Advanced Science Letter, 25 (1), 155-157.

Nashori, H.F., Iskandar, T.Z., Setiono, K., Siswadi, A.G.S., Andriansyah, Y. (2020). Religiosity, interpersonal attachment, and forgiveness among the Javanese population in Yogyakarta, Indonesia. Mental Health, Religion, and Culture, 23(1), 40-50.

Opič, S. (2016). Interpersonal relations in school. International journal of cognitive research in science, engineering and education. Vol. 4, No.2, 9-21.

Pelras, C. (2006). Manusia Bugis. (Terj. Abdul Rahman
Abu, Hasriadi \& Nurhady Sirimorok). Jakarta. Penerbit Nalar bekerjasama dengan Forum Jakarta-Paris (EFEO).

Rifai, A.M. (2007). Manusia Madura: Pembawaan, perilaku, penampilan, dan pandangan hidupnya seperti diceritakan peribahasanya. Yogyakarta: Pilar Media.

Sartini, N.W. (2009). Menggali nilai kearifan lokal budaya Jawa lewat ungkapan (bebasan, saloka dan paribasa). Jurnal Ilmiah Bahasa dan Sastra, 5(1), 28-37.

Shears, J. K., \& Furman, R. (2005). Examining interpersonal relationship predictors of delinquency across ethnic and racial samples. Child and Adolescent Social Work Journal, 22 (34), 281-299.

Singelis, T. M., Triandis, H.C., Bhawuk, D.P.S., \& Gelfand, M.J. (1995). Horizontal and vertical dimensions of individualism and collectivism: A theoretical and measurement refinement. https://doi.org/10.1177/1069397195029003 02

Su-hsing, W., \& Wei-ming, L. (2009). The effect of interpersonal relationships on psychosomatic symptoms: moderating role of gender. USChina Education Review. 6(6), 53-63.

Setiono, K. (2009). Psikologi Perkembangan. Bandung: Penerbit Widya Padjadjaran. S

Susetyo, D.P.B., Widiyatmadi, H. M. E., \& Sudiantara, Y. (2014). Konsep self dan penghayatan self orang Jawa. Psikodimensia, 13(1)

Sutarto, A. (2004). Studi pemetaan kebudayaan Jawa Timur (Studi deskriptif pembagian 10 sub kebudayaan Jawa Timur). Laporan penelitian. Jember: Program Studi Antropologi FISIP Universitas Jember.

Wijayanti, H., \& Nurwianti, F. (2010). Kekuatan karakter dan kebahagiaan pada Suku Jawa. Jurnal Psikologi. 3(2), 114-122.

Wiyata, A.L. (2002). Carok: Konflik kekerasan dan harga diri orang Madura. Yogyakarta: LKIS.

Wiyata, A.L. (2013). Mencari Madura. Jakarta: Bidik Phronesis Publishing. 